\title{
Amorphous and crystalline calcium carbonate distribution in the tergite cuticle of moulting Porcellio scaber (Isopoda, Crustacea)
}

\author{
Frank Neues ${ }^{\mathrm{a}}$, Sabine Hild ${ }^{1, \mathrm{~b}}$, Matthias Epple ${ }^{\mathrm{a}, *}$, Othmar Marti $^{\mathrm{c}}$, Andreas Ziegler ${ }^{\mathrm{b}, *}$ \\ a Institute of Inorganic Chemistry and Center for Nanointegration, University of Duisburg-Essen, Universitaetsstrasse 5-7, 45117 Essen, Germany \\ ${ }^{\mathrm{b}}$ Central Facility for Electron Microscopy, University of Ulm, Albert-Einstein-Allee 11, 89069 Ulm, Germany \\ ${ }^{\mathrm{C}}$ Department of Experimental Physics, University of Ulm, Albert-Einstein-Allee 11, D89069 Ulm, Germany
}

\section{A R T I C L E I N F O}

\section{Article history:}

Received 21 December 2010

Received in revised form 23 March 2011

Accepted 24 March 2011

Available online 30 March 2011

\section{Keywords:}

Crustaceans

Woodlice

Porcellio scaber

Moulting

Biomineralization

Cuticle

Calcite amorphous calcium carbonate

\begin{abstract}
A B S T R A C T
The main mineral components of the isopod cuticle consists of crystalline magnesium calcite and amorphous calcium carbonate. During moulting isopods moult first the posterior and then the anterior half of the body. In terrestrial species calcium carbonate is subject to resorption, storage and recycling in order to retain significant fractions of the mineral during the moulting cycle. We used synchrotron $\mathrm{X}$-ray powder diffraction, elemental analysis and Raman spectroscopy to quantify the ACC/calcite ratio, the mineral phase distribution and the composition within the anterior and posterior tergite cuticle during eight different stages of the moulting cycle of Porcellio scaber. The results show that most of the amorphous calcium carbonate (ACC) is resorbed from the cuticle, whereas calcite remains in the old cuticle and is shed during moulting. During premoult resorption of ACC from the posterior cuticle is accompanied by an increase within the anterior tergites, and mineralization of the new posterior cuticle by resorption of mineral from the anterior cuticle. This suggests that one reason for using ACC in cuticle mineralization is to facilitate resorption and recycling of cuticular calcium carbonate. Furthermore we show that ACC precedes the formation of calcite in distal layers of the tergite cuticle.
\end{abstract}

(c) 2011 Elsevier Inc. All rights reserved.

\section{Introduction}

Crustaceans possess an exoskeleton (the cuticle) of high mechanical strength that provides support of the body and protection against environmental strains including predation and, in terrestrial species, desiccation. The cuticle consists of an organic matrix composed of chitin-protein fibers and a mineral phase. In the course of growing, it is periodically shed off in a process called moulting. This process includes resorption of mineral and organic material from the old cuticle, the synthesis of the organic phase of the new cuticle before the moult, shedding of the old cuticle, expansion of the new cuticle to increase the size of the animal, and mineralization of the new cuticle mainly with $\mathrm{CaCO}_{3}$ (Passano, 1960). Since calcium ions are lost with the old cuticle crustaceans store part of the cuticular calcium that is resorbed during premoult. Marine animals store only little calcium within gastroliths and hepatopancreas because they take up calcium ions from the

\footnotetext{
* Corresponding authors. Fax: +49 2011832621 (M. Epple), +49 7315023383 (A. Ziegler).

E-mail addresses: matthias.epple@uni-due.de (M. Epple), andreas.ziegler@ uni-ulm.de (A. Ziegler).

1 Present address: Institute of Polymer Science, Johannes Kepler University, Altenbergerstrasse 52, 4040 Linz, Austria.
}

seawater after moult allowing for quick mineralization of the new cuticle to regain its protective function (Neufeld and Cameron, 1993). However, in environments with a lower availability of calcium ions like in fresh water or on land, crustaceans form large $\mathrm{CaCO}_{3}$ reservoirs that are utilized to mineralize the new cuticle (Greenaway, 1985). An interesting mode to retain calcium during moulting occurs in isopods that are unique in moulting first the posterior and then the anterior half of the body with the border between the fourth and fifth thorax segments (corresponding to the fifth and sixth somites of the pereon). This biphasic moult allows the animals to reduce the loss of $\mathrm{CaCO}_{3}$ by shifting it between the anterior and poster integument. This mode is generally utilized in terrestrial isopod species (Oniscidea) that developed large $\mathrm{CaCO}_{3}$-deposits within the ecdysial space between the new and old cuticle of the first four anterior sternites (Messner, 1965; Steel, 1993; Strus and Compere, 1996; Ziegler and Miller, 1997; Ziegler, 2003). Deposition and resorption of the deposits is well studied in the common woodlouse Porcellio scaber (Ziegler, 1996, 1997; Hagedorn and Ziegler, 2002; Ziegler et al., 2002, 2004; Fabritius and Ziegler, 2003). In P. scaber the deposits developed about 1 week before the posterior moult. During this premoult stage calcium and carbonate ions are resorbed from the posterior cuticle into the hemolymph and are then transported into the ecdysial space of the anterior sternites where it forms the deposits. When 
the sternal deposits are well developed, additional $\mathrm{CaCO}_{3}$ is stored within the anterior cuticle as indicated by a change in color resulting in a whitish appearance of the anterior dorsal part of the body including the anterior thoracic segments (tergites) (Steel, 1993; Strus and Blejec, 2001). After moult of the posterior, but before the moult of the anterior half of the body (intramoult) calcium and carbonate ions from the deposits and the anterior dorsal integument are transported back to the hemolymph and are used to mineralize the new posterior cuticle (Messner, 1965; Steel, 1993; Ziegler et al., 2007). When the deposits are completely resorbed the animal moults the anterior half of the body and the new anterior cuticle is mineralized in the postmoult stage.

Interestingly, the mineral phase of the sternal $\mathrm{CaCO}_{3}$ deposits of $P$. scaber are completely amorphous with a molar Ca:Mg ratio of 30:1 and a Ca:P ratio of 11.5:1 (Ziegler, 1994, 2002; Becker et al., 2003). The amorphous structure allows a quick dissolution of the deposits since ACC is about 10 times more soluble than calcite (Brecevic and Nielson, 1989). Recent studies on the cuticle of a number of crustaceans has shown that depending on species the cuticle consists of varying amounts of amorphous calcium carbonate, calcite and amorphous calcium phosphate (Al-Sawalmih et al., 2009; Becker et al., 2005; Boßelmann et al., 2007; Neues et al., 2007; Hild et al., 2009; Shechter et al., 2008). This suggests the possibility that ACC is preferentially resorbed from the cuticle over calcite as a result of its high solubility. This hypothesis was supported by a recent analysis of the spatial distribution of calcite and ACC in the terrestrial isopods P. scaber, Armadillidium vulgare and Titanethes albus employing $\mu$-Raman spectroscopic imaging. It revealed that calcite occurs in the apical region only, while the proximal region of the cuticle is mineralized by ACC, also suggesting preferential resorption of ACC (Hild et al., 2008, 2009). However, direct evidence for changes in the ACC/calcite distribution during the moulting cycle of crustaceans is lacking. In particular it is unknown if a significant amount of calcite is resorbed in addition to ACC.

In an attempt to investigate differential resorption of ACC and calcite and spatial aspects of mineral storage within the cuticle, we have investigated the changes in the distribution and relative amount of ACC and calcite within the anterior and posterior tergites, during the moulting cycle. For this we used a combination of synchrotron X-ray diffraction analysis, atomic absorption spectroscopy, and $\mu$-Raman spectroscopic imaging. The results suggest that an important function of cuticular ACC is to facilitate the resorption of $\mathrm{CaCO}_{3}$ during the moulting cycle.

\section{Material and methods}

\subsection{Animals}

P. scaber Latreille, 1804, were collected from local biotopes, kept in plastic containers filled with soil and bark and fed with fresh potatoes, carrots and dry oak leaves. The animals were examined daily for the appearance of white calcariferous sternal deposits that were used to determine the premoult stages. These animals were placed individually into plastic containers with a diameter of $8 \mathrm{~cm}$ containing a disc of wet paper towel and fed as described above. Animals with large but incompletely developed sternal deposits were assigned as being in the mid premoult stage (stage s4 according to Ziegler, 1997) and animals with fully developed sternal deposits and whitish coloration of the anterior dorsal cuticle as being in the late premoult stage. Animals that had shed the posterior cuticle and in which the sternal deposits were still large were denoted as animals being in the early intramoult stage and those with small sternal deposits as being in the late intramoult stage. Postmoult animals were used just after the anterior moult (early postmoult) and 1 and 2 days after the anterior moult (1d postmoult and $2 \mathrm{~d}$ postmoult, respectively). In addition we used animals 6-8 days after moulting. Since in $P$. scaber a true intermoult stage is lacking (Ziegler, 1997) these animals were assigned as being in the early premoult stage rather than intermoult stage.

\subsection{Sample preparation}

Anterior and posterior tergites were obtained by dissecting animals in $100 \%$ methanol. Previous studies have shown that ACC from sternal deposits of $P$. scaber is stable in methanol for at least 1 month (Becker et al., 2003). Subcuticular soft tissue was carefully removed from the tergites and the sample washed first in bidistilled water for $2 \mathrm{~s}$ to remove salt residues and then in $100 \%$ methanol for at least $5 \mathrm{~s}$ to remove the water. Then the samples were air dried at room temperature and stored at $-20^{\circ} \mathrm{C}$ until further use.

For scanning confocal $\mu$-Raman spectroscopy ( $\mathrm{SC} \mu$-RS) pieces of the tergites were glued onto polymethylmetacrylate (PMMA) holders using superglue. Tergites were cut sagittally using a Reichert Ultracut ultramicrotome and glass knifes to obtain a plane surface. This surface was then polished with a diamond knife by successively cutting and advancing the specimen 15 times each by 70 , 40 and $20 \mathrm{~nm}$.

\subsection{Field emission scanning electron microscopy}

For SEM analysis cuticle samples on PMMA holders were cleaved in the sagittal plane and rotary-shadowed with $3 \mathrm{~nm}$ platinum (BAF 100, Balzers) at an angle of $45^{\circ}$. SEM micrographs were recorded with a field emission scanning electron microscope (FESEM) (Hitachi S-5200) at an acceleration voltage of $4 \mathrm{kV}$.

\subsection{X-ray powder diffractometry}

High-resolution X-ray powder diffractometry was carried out in transmission geometry at room temperature (ground samples on Kapton foil) at beamline B2 at HASYLAB/DESY, Hamburg, Germany, at a wavelength of $\lambda=0.47176 \AA$ (Knapp et al., 2004a,b). All data were converted to $\mathrm{Cu} \mathrm{K} \alpha_{1}$ radiation wavelength $(\lambda=1.54056 \AA)$ for better comparison. For quantitative Rietveld analyzes ( $Q R A)$, the cuticle was mixed with crystalline quartz $\left(\mathrm{SiO}_{2}\right)$ in a $5: 1=w: w$ ratio, followed by thorough grinding. This mixture was subjected to X-ray powder diffraction as described above. The obtained diffractograms were analyzed by the Rietveld software FULLPROF Suite 2005 (Rodriguez-Carvajal, 1990) which gave the relative mass fractions of calcite and quartz, the unit cell parameters and the reflex positions. Thereby, the amount of crystalline calcite in the cuticle was determined. The accuracy of this method is discussed in the literature (Gualtieri, 2000). Due to magnesium replacing calcium in the crystal lattice, the peak intensities and the phase scale factors during Rietveld refinement are affected. Furthermore, minor variations in the intensity occurred due to the biological origin of the samples and the resulting preferred orientation. Therefore, we assumed a relative error of about $5 \%$. The amount of magnesium in calcite was determined by analyzing the peak shifts induced by the ionic substitution of calcium by magnesium using the method of Goldsmith (Goldsmith and Graf, 1958). The unit cell parameters $a$ and $c$ are decreasing and the position of the (104) reflex is shifted to larger angles with increasing content of magnesium.

Calcium and magnesium contents were determined by atomic absorption spectroscopy (AAS) in a Unicam 939 instrument after extraction of calcium from the cuticle by suprapure $\mathrm{HCl}$ (average from two determinations). Typically the variation between the 
two measurements was $0.2 \mathrm{wt} . \%$ or less. The content of calcium carbonate was computed from the calcium content as $\mathrm{w}(\mathrm{Ca}-$ $\left.\mathrm{CO}_{3}\right)=\mathrm{w}(\mathrm{Ca}) \mathrm{M}\left(\mathrm{CaCO}_{3}\right) / \mathrm{M}(\mathrm{Ca})$. In contrast to our earlier studies on crustacean cuticles (Becker et al., 2005; Boßelmann et al., 2007; Neues et al., 2007), no thermogravimetric data could be recorded due to the small amount of sample. Thus, the amount of ACC was estimated as difference between the total amount of calcium carbonate and the amount of crystalline calcite obtained by Rietveld refinement. The content of amorphous calcium phosphate (ACP) could not be determined due to the small amount of sample and was neglected.

\subsection{Raman spectroscopy and imaging}

A confocal Raman microscope (WITec, Ulm, Germany) equipped with a NdYag laser (wavelength of $532 \mathrm{~nm}$ ) for excitation and a Nikon $100 \times(\mathrm{NA}=0.95)$ objective were used to locate calcite, ACC and organic matrix within the tergite cuticle by recording single Raman spectra and Raman spectral images. As reference material for the Raman measurements, calcite was precipitated from a solution containing $24 \mathrm{mmol} \mathrm{L}^{-1} \mathrm{Ca}^{2+}$ and $24 \mathrm{mmol} \mathrm{L}^{-1} \mathrm{CO}_{3}^{2-}$ at $\mathrm{pH}$ 8.6. Amorphous calcium carbonate without any organic additives was synthesized by the method described by Faatz et al. (2004). Purified chitin from crab-cuticles (Sigma-Aldrich) and bovine serum albumin (BSA) (VWR International) served as chitin and protein reference materials, respectively. The Raman spectra of the standards were recorded with integration times of $5 \mathrm{~s}$.

Sagittally cut and polished surfaces of the cuticles were prepared and analyzed in single imaging and in the Raman spectral imaging mode. To get high resolution Raman images, the samples were scanned point-by-point and line-by-line, and Raman spectra between 0 and $3750 \mathrm{~cm}^{-1}$ were recorded with an integration time of $250 \mathrm{~ms}$ at every pixel (Pixel density: 10 spectra at $1 \mu \mathrm{m}$ ). Images were obtained analyzing the integral of specific bands above background employing the WITecProject software (Version 1_86, WITec, Ulm, Germany) (Schmidt et al., 2005). To determine the distribution of calcite, carbonate in total, and organic material we used the peak areas for the lattice vibration at $280 \mathrm{~cm}^{-1}$, for $\mathrm{CO}_{3}^{2-}$ stretching vibration, and that of the band at 2800$3020 \mathrm{~cm}^{-1}$, which is specific for $\mathrm{CH}_{3}$ stretching vibration, respectively. All images were color-coded in a way that higher values of the integral sum which correlates to a higher amount of a specific component appear brighter. For the different materials color tables were chosen as following: calcite (red), carbonate (orange), and organic components (green).

The overall Raman spectrum for a tergite cuticle of $P$. scaber was obtained by averaging spectra collected along a $10 \mu \mathrm{m}$ wide area across the polished surface of the sample. These spectra were used to calculate the ACC/calcite ratio. The spectra were fitted by a linear combination of normalized ACC $\left(S_{\text {ACC }}\right)$, calcite $\left(S_{\text {calcite }}\right)$ and chitin $\left(S_{\text {chitin }}\right)$ reference spectra.

$S_{\text {sample }}=a \cdot S_{\text {ACC }}+b \cdot S_{\text {calcite }}+c \cdot S_{\text {chitin }}$

The ratio a/b of the coefficients obtained for $S_{\text {ACC }}$ and $S_{\text {calcite, }}$ respectively, was used to present the $A C C /$ calcite ratio.

To get high resolution Raman line scans, the samples were collected point-by-point across the polished surface of the sample. Raman spectra between 0 and $3750 \mathrm{~cm}^{-1}$ were recorded with an integration time of $1 \mathrm{~s}$ at every pixel (Pixel density: $10 \mathrm{pixel} / \mu \mathrm{m}$ ). The line scans were obtained in the same way as Raman images by analyzing the integral of specific bands above background employing the WITecProject software. For each moulting stage tergites of 2-4 animals were used. For each tergite we recorded 2-3 line scans at three different locations.

\section{Results}

\subsection{Field emission scanning electron microscopy (FESEM)}

The ultrastructure of the mineralized tergite cuticle from intermoult animals was already described in previously (Hild et al., 2008). Here we therefore just show FESEM micrographs of selected moulting stages (Figs. 1 and 2). During late premoult the cuticle of the anterior tergites resembles those in intermoult, except, that just proximal of the unmineralized membranous layer a new layer appears that contains numerous spherules with diameters of about $200 \mathrm{~nm}$ that are interconnected by strands of an organic matrix (Fig. 1A and B). The spherules are composed of small granules about $20 \mathrm{~nm}$ in size. This layer and considerable amounts of mineral within the anterior cuticle are resorbed before the cuticle is shed (see Raman spectroscopic images below). The tergites of the posterior exuviae are about $6 \mu \mathrm{m}$ thick in late premoult (Fig. 1C). The exocuticle appears intact. In particular the distal part of the exuviae including an outer smooth layer (Hild et al., 2008) is still fully mineralized (Fig. 1D). Fibrous structures within the proximal regions of the exocuticle and the distal region of the endocuticle indicate partial demineralization (Fig. $1 \mathrm{C}$ and $\mathrm{E}$ ). In the proximal part of the endocuticle the organic and inorganic material is almost completely resorbed leaving only a thin degradation zone of smooth appearance (Fig. 1C).

An example of the posterior cuticle during early intramoult is shown in Fig. 2. The new exocuticle appears already well mineralized (Fig. 2A and B). Higher magnification reveals a granular texture of the smooth layer and more proximal regions of the exocuticle (Fig. 2B).

The endocuticle is not yet fully synthesized. Most regions of the endocuticle that are present are already mineralized to some extent (Fig. 2A and C). However, still fibrous structures are visible and pore canals are devoid of mineral (Fig. 2C). Only an about $0.5 \mu \mathrm{m}$ thick proximal layer consists of unmineralized fibers of the organic matrix (Fig. 2D).

\subsection{The ACC/calcite ratio}

A typical X-ray powder diffractogram and the superimposed diffractogram calculated according to the Rietveld refinement are shown for a sample containing $5.66 \mathrm{mg}$ of the tergal cuticle mixed with $0.63 \mathrm{mg}$ quartz (Fig. 3). The diffractograms indicate the presence of calcite within the samples and the virtual absence of crystalline calcium phosphate. The amount of crystalline magnesium calcite determined according to the Rietveld refinement are given for the anterior and posterior tergite cuticle of each moulting stage (Table 1). Small shifts in the peak position are due to magnesium replacing calcium within the calcite crystal lattice. The magnesium concentration within the crystal lattice as determined by the Goldsmith method was between 0.1 and $0.2 \mathrm{wt} . \%$. AAS indicates that the amount of magnesium not in Mg-calcite is about five times higher than that within the calcite lattice. In all moulting stages, AAS of anterior and posterior cuticle samples yielded calcium concentrations that exceed the amount of calcium expected from the amount of calcite within the samples (Table 1), indicating that a significant amount of calcium occurs in the form of ACC or amorphous calcium phosphate (ACP). Because of the small sample size (see Section 2) we did not distinguish between ACP and ACC by performing TG analysis. For the sake of simplicity, we assumed that all non-calcite calcium would occur in the form of ACC, although we know that in the early premoult stage the cuticle of the tergites contains 12 wt.\% ACP (Becker et al., 2005). Because of changes in the mass of the cuticle between moulting stages due to resorption/ 

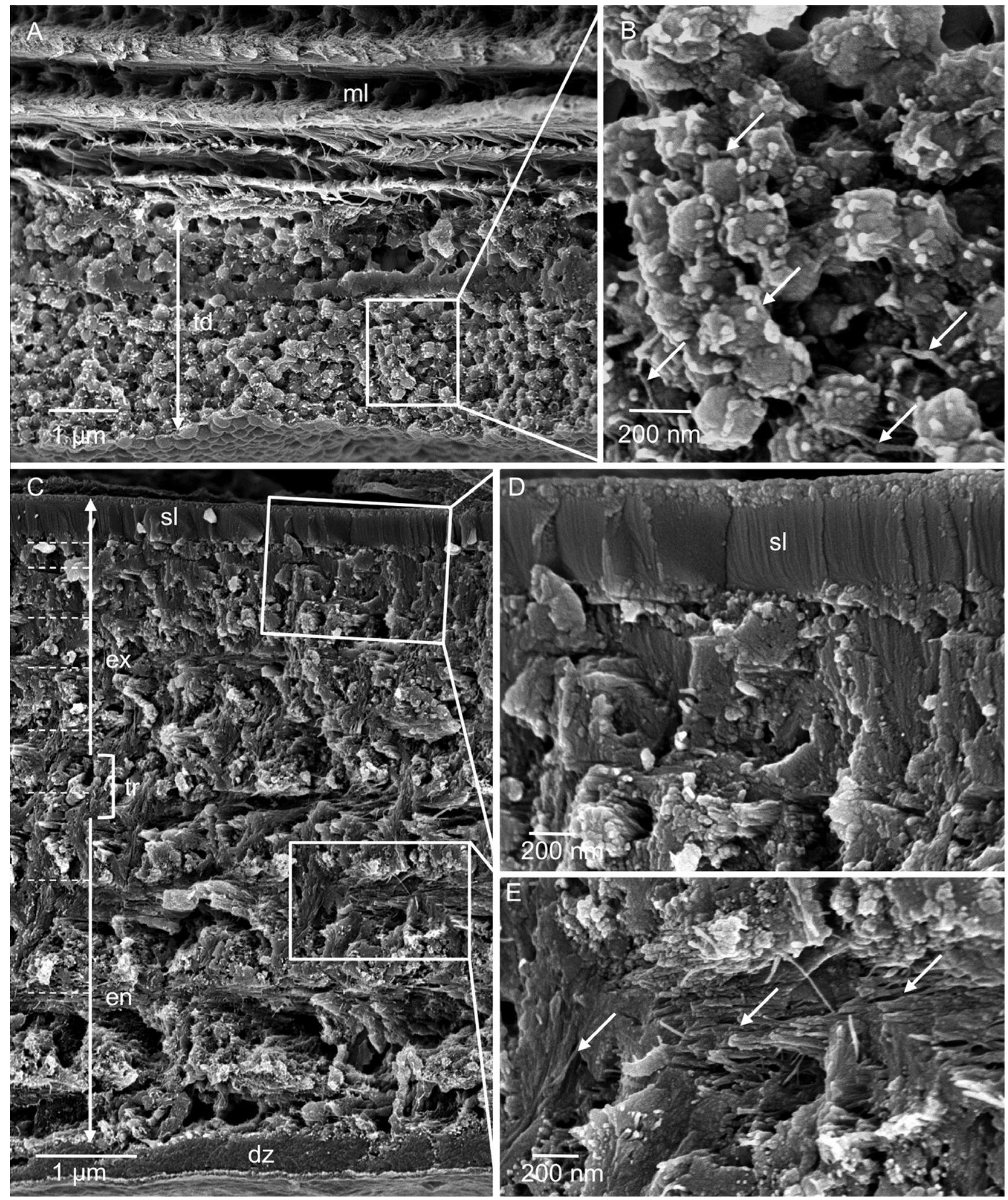

Fig. 1. Field emission scanning electron micrographs of the anterior cuticle of $P$. scaber during late premoult (A and B) and of the posterior exuviae (C-E). Proximally of the membranous layer $(\mathrm{ml})$ lies a tergal deposit $(\mathrm{td})$ consisting of a layer of spherules with diameters of $200 \mathrm{~nm}(\mathrm{~A})$. The spherules are composed of about $20 \mathrm{~nm}$ thick granules and are interconnected by filamentous material (arrows). The distal part of the exocuticle (ex) of the posterior exuviae is still well mineralized (C and D). Proximal regions of the cuticle appear partly demineralized ( $\mathrm{C}$ and $\mathrm{E}$ ) as indicated by strand-like structures (arrows) of the organic matrix. en, endocuticle; tr, region of the transition between ex an en. A smooth degradation zone $(\mathrm{dz})$ lies proximally of the exuviae.

secretion of mineral and organic material only mass-invariant values can be compared. Therefore we calculated virtual ACC/ calcite ratios for each moulting stage (Fig. 4). The resorption of mineral from the posterior cuticle is accompanied by a reduction of the $\mathrm{ACC} /$ calcite ratio within the posterior tergites by 1.08 units from early premoult to late premoult. Concomitant to this 

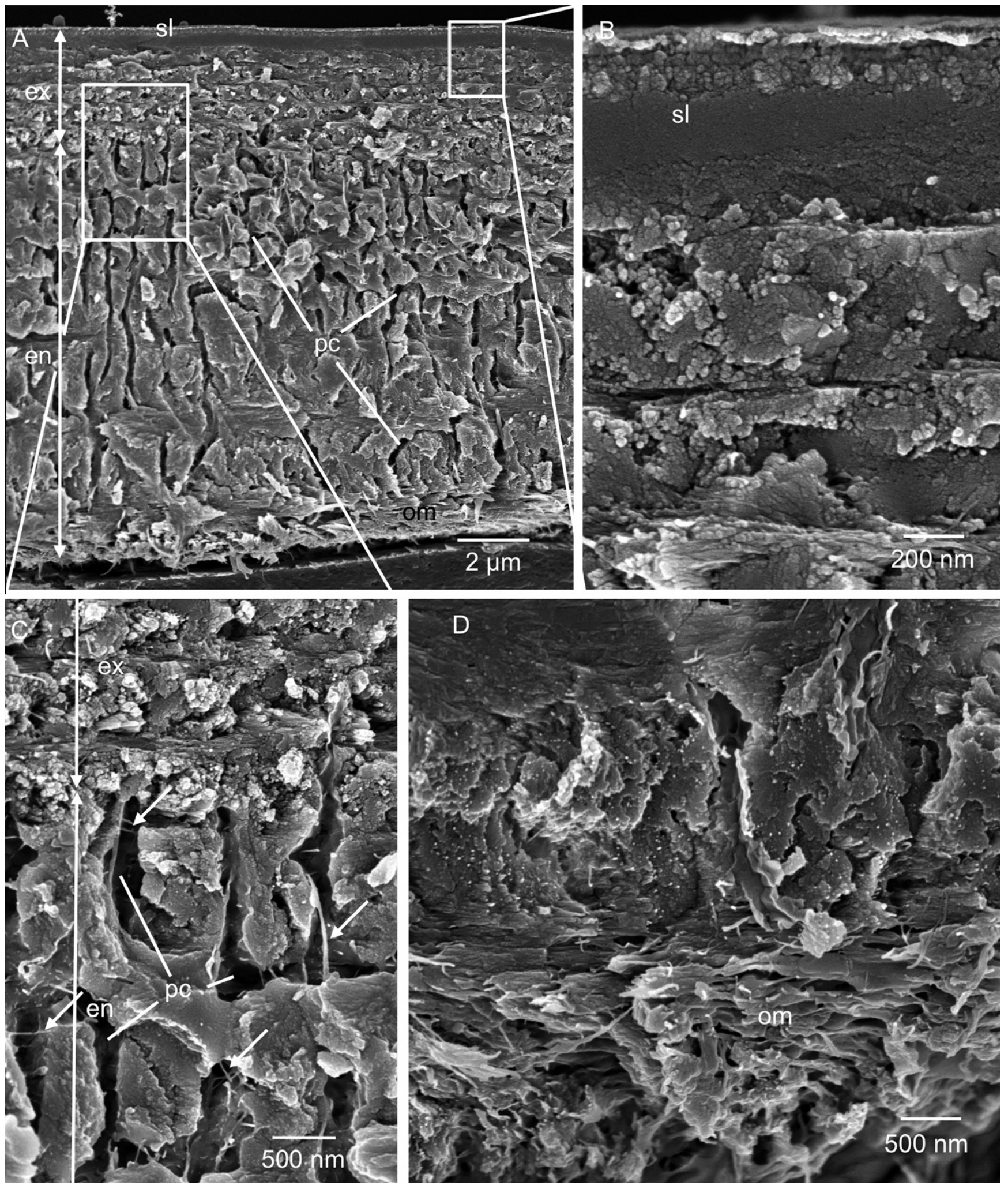

Fig. 2. Field emission scanning electron micrographs of the mineralizing posterior cuticle of $P$. scaber during early intramoult. (A) Overview, showing mineralized exo (ex) and partly mineralized endocuticle (en) containing many pore canals. The well-mineralized exocuticle and its distal smooth layer (sl) have a granular texture (B). (C) Detail of the transition zone between exo and endocuticle. Empty pore canals (pc) and filaments (arrows) of the organic matrix are apparent. (D) Proximal region of the endocuticle. The very proximal organic matrix (om) appears still unmineralized.

decrease the ratio in the anterior tergites increases by 0.74 . Until posterior ecdysis the ACC/calcite value within the posterior cuticle decreases further by 0.15 units to the value within the exuviae (Fig. 4A). Between the posterior moult and the time of collection of the posterior exuviae in early intramoult, some of the mineral within the anterior tergites is already resorbed for 


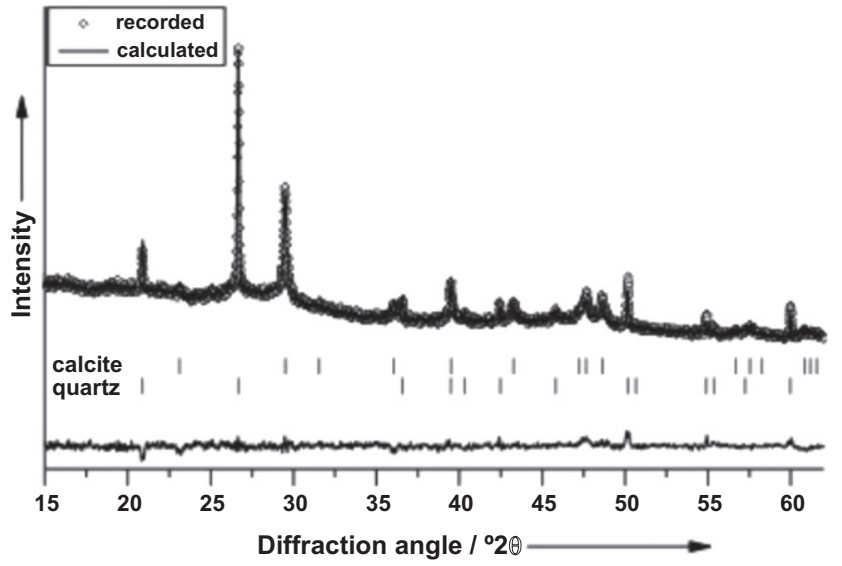

Fig. 3. Synchrotron X-ray powder diffractogram of the cuticle of $P$. scaber (posterior, late premoult). Five parts of cuticle were mixed with one part of crystalline quartz $\left(\mathrm{SiO}_{2}\right)$. A Rietveld refinement with recorded and calculated data (upper curve) is shown. The positions of the corresponding X-ray peaks for calcite $\left(\mathrm{CaCO}_{3}\right)$ and quartz are indicated. The lower curve shows the difference plot (calculated minus recorded). The evaluation of the Rietveld refinement allows a quantitative determination of the mass fraction of crystalline calcite. The analysis of the calcite peak positions allows the computation of the content of magnesium in calcite by the Goldsmith method.

mineralization of the new posterior cuticle, resulting in a small decrease in the $\mathrm{ACC} /$ calcite value by 0.37 units (Fig. 4B). In late intramoult the mineralising $\mathrm{ACC} /$ calcite ratio of the new posterior cuticle increases to a value 1.66 units higher than in the exuviae and even 0.43 units higher than in the early premoult control stage. Surprisingly, the ACC/calcite ratio within the posterior tergites decreases by 0.78 units from late intramoult to early postmoult. The mineralization of the new posterior tergites is accompanied by a decrease of the ACC/calcite ratio in the anterior tergites by 1.4 units from late premoult to the value within the anterior exuviae. During further mineralization of the posterior cuticle the ACC/calcite ratio increases by 1.1 units within 1 day from early postmoult, followed by a decrease of 0.25 units during the next day. One day after the anterior moult the $\mathrm{ACC} /$ calcite ratio of the mineralising anterior tergite cuticle is 0.61 units larger than during early premoult and increases further by 0.69 units during the next day.

In both the posterior and anterior tergite cuticle the ACC/calcite ratio decreases within 4-6 days from the second day of postmoult to early intramoult by 0.50 and 1.30 units, respectively.
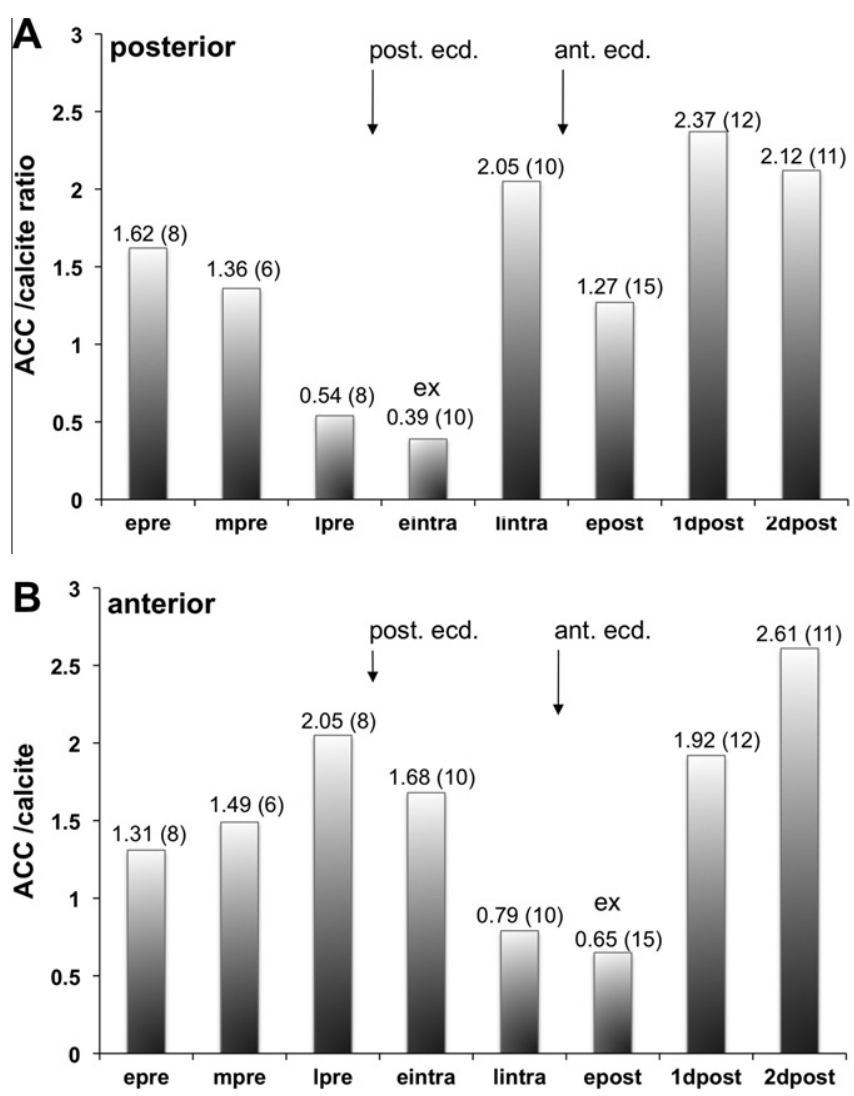

Fig. 4. The weight ratio of amorphous calcium carbonate (ACC) to crystalline Mgcalcite in the anterior and posterior tergite cuticles during eight moulting stages as determined by combined quantitative Rietveld analysis and atomic absorption spectroscopy. 1dpost: 1 day after postmoult, 2dpost: 2 days after postmoult, eintra: early intramoult, epost, early postmoult, epre: early premoult, lpre: late premoult, mpre: mid premoult.

\subsection{Raman imaging}

Fig. 5A and B present integral spectra calculated from the individual spectra obtained during a scan over a sagittal microtome polished surface of tergite cuticle in early premoult and the posterior exuviae, respectively. Comparing these spectra with the reference spectra for synthetic ACC, purified chitin, BSA and synthetic calcite (Fig. 5C-F) reveal that in the exuviae the signal for calcite

Table 1

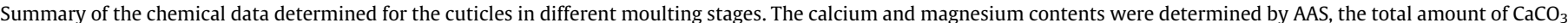

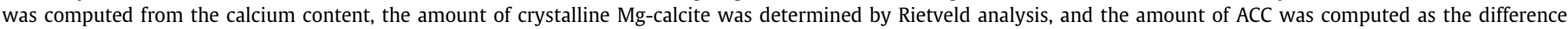
between the contents of $\mathrm{CaCO}_{3}$ and crystalline $\mathrm{Mg}$-calcite. All data are given in wt.\%.

\begin{tabular}{|c|c|c|c|c|c|c|}
\hline Stage & Part & $\mathrm{Ca}$ & $\mathrm{Mg}$ & $\mathrm{CaCO}_{3}$ & Cryst. Mg-calcite & ACC \\
\hline \multirow[t]{2}{*}{ Early premoult } & post & 21.8 & 0.48 & 54.5 & 20.8 & 33.7 \\
\hline & ant & 21.1 & 0.52 & 52.7 & 22.9 & 29.8 \\
\hline \multirow[t]{2}{*}{ Mid premoult } & post & 20.0 & 0.60 & 49.9 & 21.1 & 28.8 \\
\hline & ant & 18.9 & 0.59 & 47.3 & 19.0 & 28.3 \\
\hline \multirow[t]{2}{*}{ Late premoult } & post & 21.7 & 0.65 & 54.1 & 35.2 & 18.9 \\
\hline & ant & 21.6 & 0.66 & 53.9 & 17.7 & 36.2 \\
\hline \multirow[t]{2}{*}{ Early intramoult moult } & post (exuviae) & 25.5 & 0.62 & 63.7 & 45.8 & 17.9 \\
\hline & ant & 21.0 & 0.63 & 52.5 & 19.6 & 32.9 \\
\hline \multirow[t]{2}{*}{ Late intramoult } & post & 23.1 & 0.58 & 57.6 & 18.9 & 38.7 \\
\hline & ant & 21.0 & 0.57 & 52.5 & 29.3 & 23.2 \\
\hline \multirow[t]{2}{*}{ Early postmoult } & post & 21.8 & 0.58 & 54.5 & 24.0 & 30.5 \\
\hline & ant (exuviae) & 25.3 & 0.72 & 63.3 & 38.3 & 25.0 \\
\hline \multirow[t]{2}{*}{1 Day postmoult } & post & 22.0 & 0.52 & 54.9 & 16.3 & 38.6 \\
\hline & ant & 24.0 & 0.61 & 60.0 & 20.6 & 39.4 \\
\hline \multirow[t]{2}{*}{2 Day postmoult } & post & 24.3 & 0.53 & 60.7 & 19.5 & 41.2 \\
\hline & ant & 22.5 & 0.58 & 56.2 & 15.6 & 40.6 \\
\hline
\end{tabular}




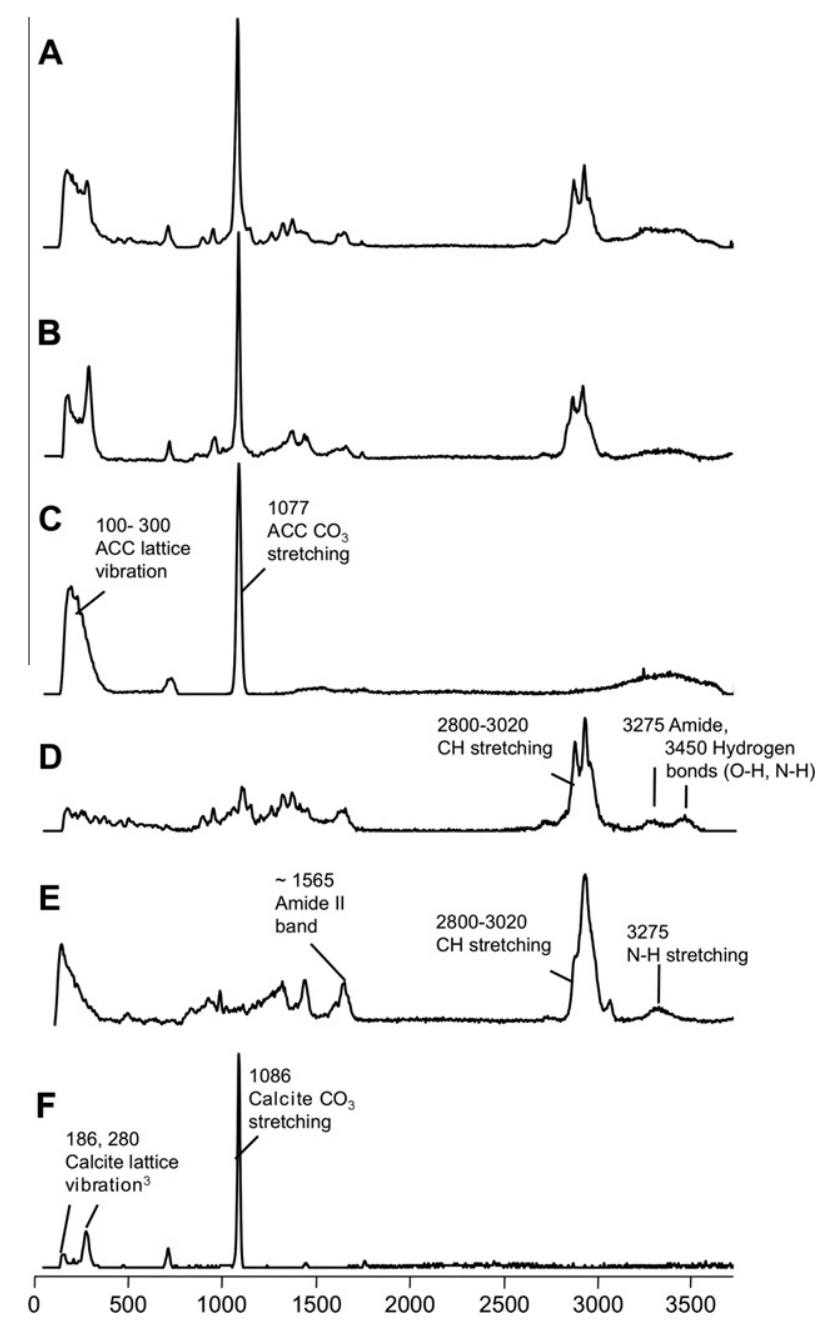

Fig. 5. Averaged Raman spectra of (A) the anterior tergite during early premoult, and (B) the anterior exuviae obtained from Raman spectroscopic images, and reference spectra of (C) synthetic ACC, (D) purified chitin from crab cuticles, (E) BSA as a protein standard and (F) synthetic calcite.

at $280 \mathrm{~cm}^{-1}$ is larger and the broad band between 100 and $300 \mathrm{~cm}^{-1}$ that is typical for presence of ACC, is smaller than in the cuticle from an early premoult animal. The organic matrix consists of chitin and protein.

Micro Raman spectroscopic images of calcite, carbonate in total, and organic material reveal changes in the distribution of these components during the moulting cycle of P. scaber (Fig. 6). From these images it is apparent that during mineral resorption in the posterior sternal cuticle the amount of calcium carbonate and of organic material decreases from the early premoult to that in the exuviae collected in early intramoult. Concomitant to these changes the thickness of the cuticle decreases (Fig. 6A). The changes in the calcite distribution are small and may result from intraspecific variations between the animals. In the cuticle of the anterior tergites there appears to be no change in the distribution of $\mathrm{CaCO}_{3}$, calcite and organic material between early premoult and mid premoult, however, in late premoult an additional layer of non-calcitic $\mathrm{CaCO}_{3}$ that also contains organic material appears at the base of the cuticle, clearly below the non-mineralized membranous layer (Fig. 6B). In contrast to the membranous layer that is composed of little protein and large amounts of chitin the additional mineralized layer contains high amounts of proteins and less chitin (data not shown). In early intramoult this additional $\mathrm{CaCO}_{3}$ layer has disappeared. During the mineralization of the new

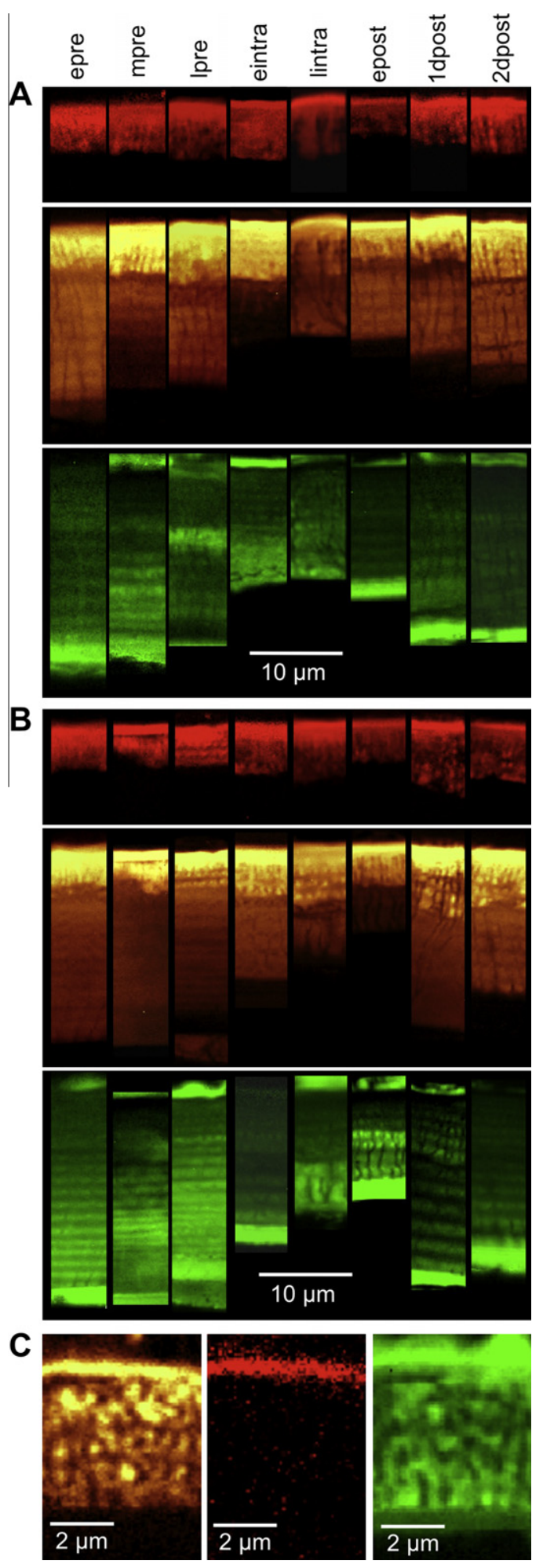

Fig. 6. Raman spectroscopic images recorded from sagittally cleaved and microtomepolished surfaces of posterior (A) and anterior (B) tergite cuticles of $P$. scaber during various stages of the moulting cycle. The images provide the distribution of carbonate (orange), calcite (red) and organic matrix (green). Calcite is located in the exocuticle whereas calcium carbonate occurs within the whole endocuticle. The epicuticle and the membranous layer are devoid of mineral. 1 dpost: 1 day after postmoult, 2 dpost: 2 days after postmoult, eintra: early intramoult, epost, early postmoult, epre: early premoult, lpre: late premoult, mpre: mid premoult. (C) Raman spectroscopic images recorded from sagittally cleaved and microtome-polished surfaces of the posterior tergite cuticle of $P$. scaber sampled $1 \mathrm{~h}$ after the posterior moult. Carbonate (orange) occurs within an about $4 \mu \mathrm{m}$ thick layer of the exocuticle. Calcite (red) formation has already started within a thin layer at the distal side of the exocuticle. Only a thin layer of the organic matrix (green) at the proximal side of the developing cuticle appears unmineralized. 

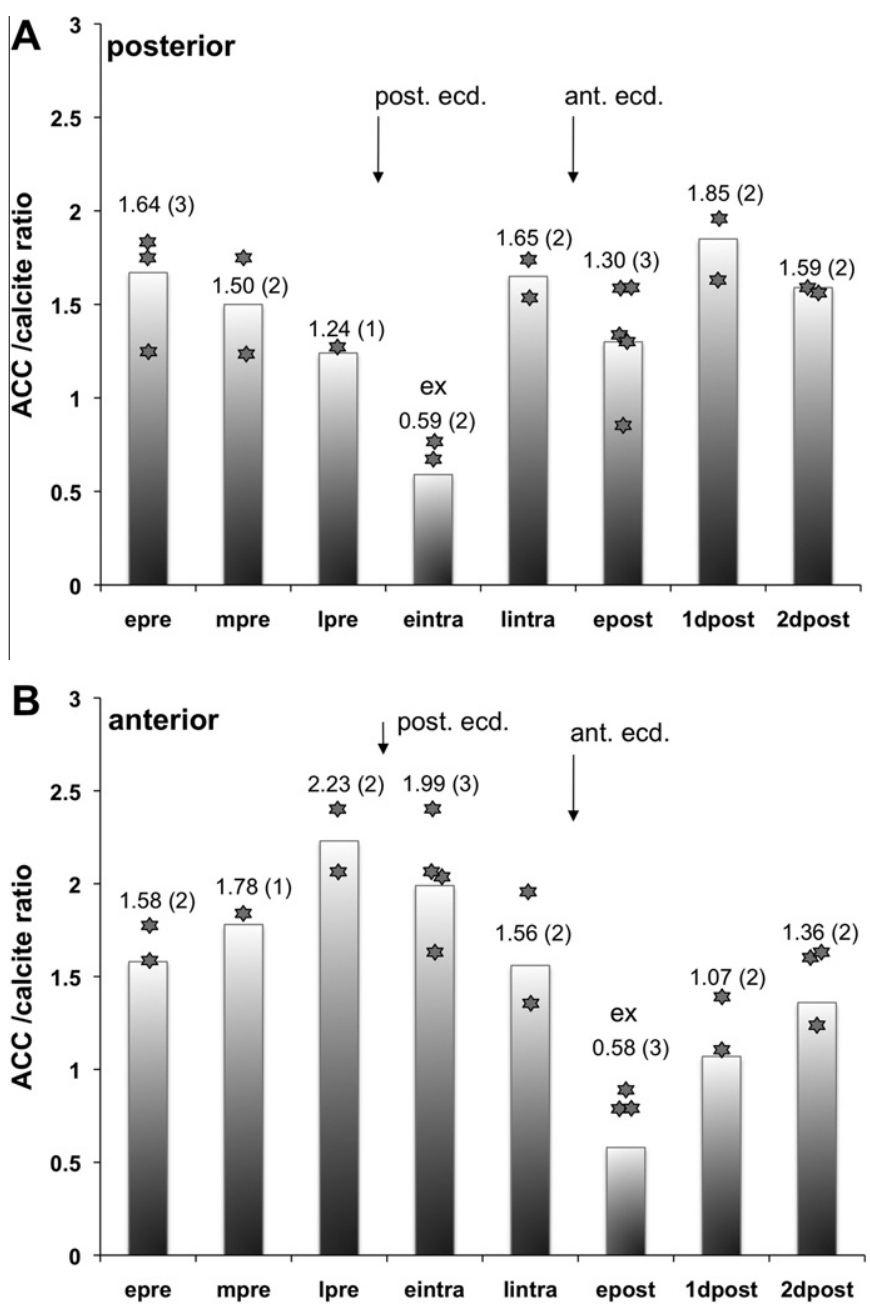

Fig. 7. Ratio of amorphous calcium carbonate (ACC) to calcite in the anterior and posterior tergite cuticles of $P$. scaber during eight moulting stages as determined by quantitative evaluation of the averaged spectra created from Raman spectroscopic images. 1 dpost: 1 day after postmoult, 2dpost: 2 days after postmoult, eintra: early intramoult, epost, early postmoult, epre: early premoult, lpre: late premoult, mpre: mid premoult.

posterior cuticle the amount of $\mathrm{CaCO}_{3}$ and organic material increase in the posterior tergites from late intramoult to the stage 2 days after the anterior moult and further within the next 4-6 days to the early premoult stage (Fig. 6A). Concomitant to the mineralization of the posterior cuticle the amount of $\mathrm{CaCO}_{3}$ and organic material decrease in the anterior tergite cuticle from late premoult until ecdysis of the anterior exuviae that were collected during early postmoult (Fig. 6B). The new anterior cuticle is already well mineralized 1 and 2 days after the posterior moult, and the amount of calcium carbonate and organic material increases further during the next 4-6 days until early premoult.

In an attempt to analyze an early mineralization step we imaged the new posterior cuticle just $1 \mathrm{~h}$ after the posterior moult (Fig. 6C). In this stage a more than $4 \mu \mathrm{m}$ thick mineralized layer has been already formed. This layer contains calcium carbonate, however, only the distal $200-300 \mathrm{~nm}$ in the form of calcite. The proximal part of the mineralized layer contains ACC in a rather patchy distribution. The Raman image of the organic matrix indicates that the whole cuticle is only little thicker than the mineralized layer. Not mineralized are the thin distal epicuticle and a less than $1 \mu \mathrm{m}$ thick proximal layer (Fig. 6C).

Fig. 7 gives an example for the estimation of the ACC/calcite ratio from the $\mathrm{SC} \mu$-RSI data of tergite cuticles. The ratios for both the
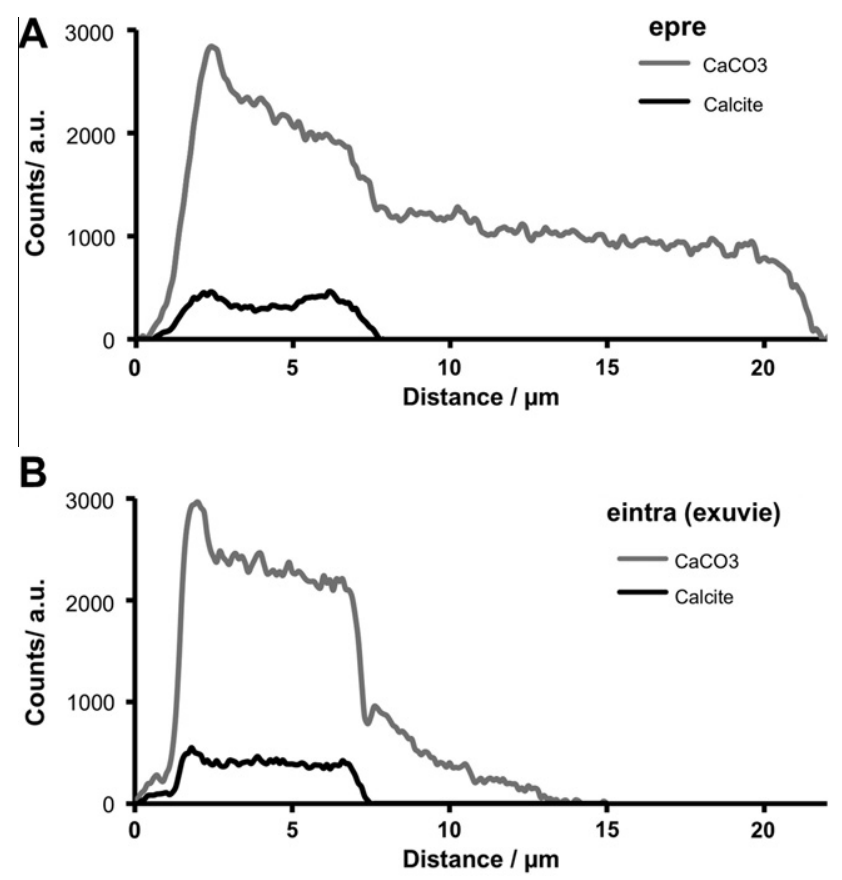

Fig. 8. Line scans across sagittal planes of the posterior tergite cuticle of $P$. scaber. Comparing a posterior tergite from the early premoult stage (epre) with the tergite of the exuviae (eintra) reveals that the thickness of the calcite-rich exocuticle is equal for both samples whereas the total thickness of the mineralized part of the tergites is reduced in the exuviae. This indicates that mainly ACC is resorbed.
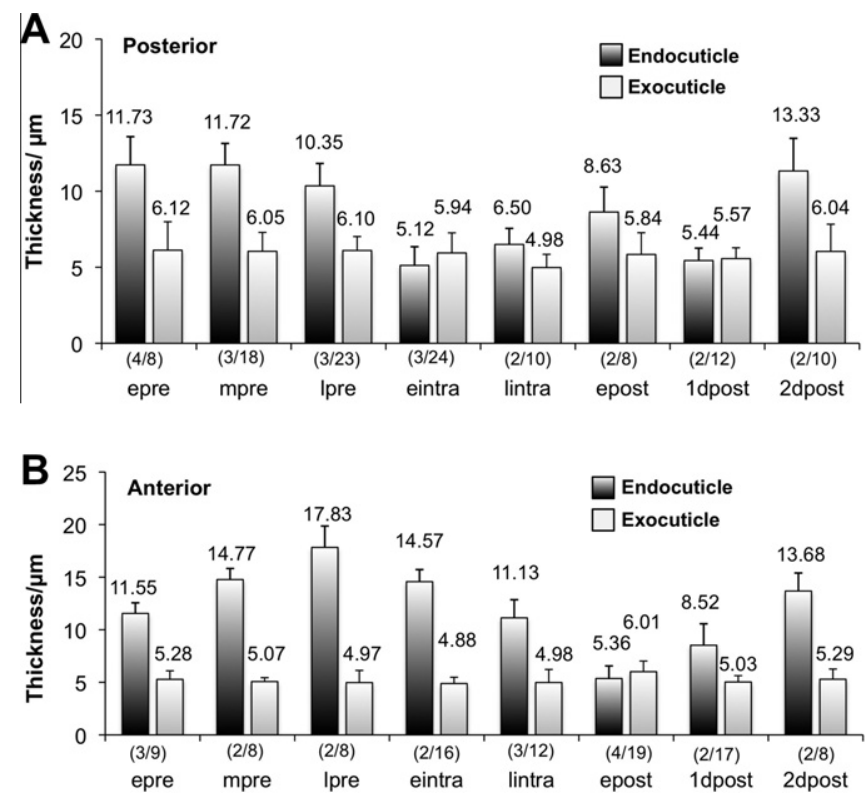

Fig. 9. Mean values for the thickness of the calcite-containing exocuticle and that of the endocuticle were determined from line scans recorded from tergites of $P$. scaber at the different moulting stages. For both posterior (A) and anterior (B) samples the thickness of the exocuticle shows only small variations. Variations in the thickness of the endocuticle can be attributed to the resorption of and mineralization with ACC. The numbers on top of the error bars denote the mean values. The numbers in parentheses below the $x$-axis give the number of animals before and the number of records after the slash. 1dpost: 1 day after postmoult, 2dpost: 2 days after postmoult, eintra: early intramoult, epost, early postmoult, epre: early premoult, lpre: late premoult, mpre: mid premoult. Error bars give the standard deviation.

anterior and posterior tergites obtained by this method largely confirm the overall trend of changes estimated by the combination of QRA and AAS (Fig. 2). Also the ratio values are mostly similar in the posterior tergites from early premoult to early intramoult 

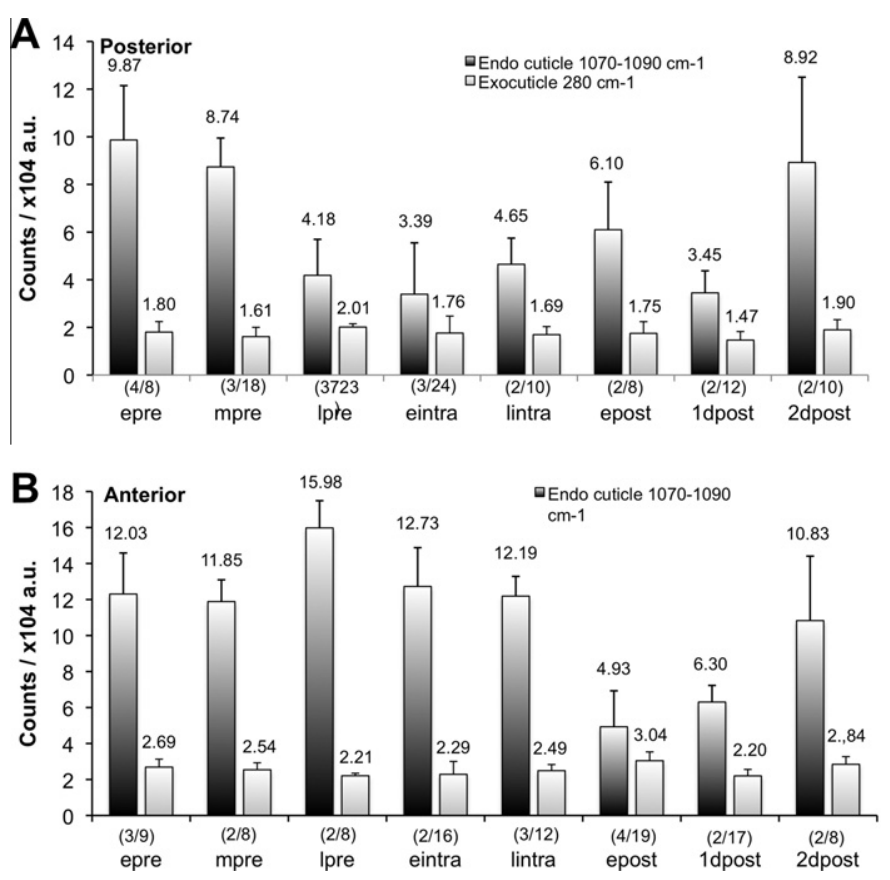

Fig. 10. Mean values for the thickness of the integral intensity of the Raman counts of the band for calcite lattice vibration at $280 \mathrm{~cm}^{-1}$ within the exocuticle, and that of the band for carbonate stretching vibration between 1070 and $1090 \mathrm{~cm}^{-1}$ within the endocuticle, as determined from line scans recorded from posterior (A) and anterior (B) tergites of $P$. scaber at different moulting stages. The amount of calcite is nearly constant within the various moulting stages. Large changes related to moulting occur in the amount of ACC within the endocuticle. Numbers on top of the error bars denote the mean values. The numbers in parentheses below the $x$-axis give the number of animals before and the number of records after the slash. 1dpost: 1 day after postmoult, 2dpost: 2 days after postmoult, eintra: early intramoult, epost, early postmoult, epre: early premoult, lpre: late premoult, mpre: mid premoult. Error bars give the standard deviation.

(exuviae) and in the anterior tergites from early premoult to early postmoult (exuviae), with the exception of the values in late premoult for the posterior tergites and in late intramoult for the anterior tergites. These differences between the values obtained by the two methods may be explained by intraspecific variations between individual animals. It appears that during the mineralization of the new posterior tergites from late intramoult to the second day after the anterior moult and of the new anterior tergites from 1 to 2 days after the anterior moult the values obtained by quantitative $\mathrm{SC} \mu$ RSI analysis lead, in almost all cases, to considerably lower values than combined QRA and AAS. Intraspecific variations cannot be completely discounted for this difference. However, because of the similarity of the trend during the moulting cycle, it appears likely that the difference in the values is due to the application of different methods. In fact statistical analysis of the pooled data from tergites sampled 1 and 2 days after the anterior moult revealed a significant difference (two tailed unpaired t-test, $p<0.01$ ) between the means \pm SD $(n)$ of $2.26 \pm 0.30$ (4) and $1.47 \pm 0.36$ (8) analyzed by QRA/AAS and SC $\mu$-RSI, respectively. See the Section 4 for further evaluation of differences obtained by the two methods.

Fig. 8 shows two examples from Raman spectroscopic line scans for carbonate and calcite across the sagittal planes of anterior tergite cuticles. When comparing a tergite from the early premoult stage with the tergite of the exuviae the scans show that mainly ACC from the endocuticle is resorbed and that calcite within the exocuticle remains more or less unchanged. The difference between the total thickness of the mineralized part of the tergites determined from the carbonate signal and the exocuticle thickness will result in the thickness of endocuticle where only ACC can be found. From line scans like those in Fig. 8 we plotted mean values for the thickness of the calcite containing exocuticle and that of the endocuticle (Fig. 9). To quantify the amount of calcite and ACC in the exocuticle and the endocuticle, the total amount of the Raman counts of the integral intensity of the band for calcite lattice vibration at $280 \mathrm{~cm}^{-1}$ in the exocuticle region and the total amount of the Raman counts of the band for the carbonate stretching vibration in the endocuticle are determined (Fig. 10). It is important to note that differences between the stages reflect also moult-independent differences in cuticle thickness and mineral content in addition to moult related changes. Nevertheless, the plots show that the thickness and the calcite content within the exocuticle, vary only within a small range and do not follow the large mostly moult related changes in the thickness and ACC content of the endocuticle (Figs. 9 and 10). Therefore, the variations of the values within the exocuticle are likely due to intraspecific variations rather than moult related events. This gives indication that during mineral resorption apparently no calcite is dissolved and also that no ACC is transformed to calcite. Furthermore, it appears that the calcite layer is quickly reformed within less than 1 day. The thickness and ACC content of the endocuticle show strong changes during the moulting cycle that appear to be mostly but not always due to resorption and deposition of ACC. However, the overall trend shows that the thickness of the endocuticle and the content of ACC decrease when mineral is resorbed, and increase during mineralization (Figs. 9 and 10).

\section{Discussion}

The results of the present study indicate that ACC within the cuticle of terrestrial isopods play an important role during repeated storage and recycling of $\mathrm{CaCO}_{3}$ within the integument. For the first time we show by combined QRA and AAS and SC $\mu$-RSI that most of the amorphous calcium carbonate (ACC) is resorbed from the cuticle, whereas calcite remains in the old cuticle and is shed during moulting. Furthermore we show that in the isopod exocuticle, ACC functions as a precursor phase for calcite during biomineralization.

\subsection{Resorption and storage of ACC}

The decrease in the $\mathrm{ACC} /$ calcite ratio within the posterior and anterior tergites during the stages of mineral resorption, as revealed by combined QRA and AAS are in accordance with a preferential resorption of ACC over calcite. An increase in the amount of calcite can be excluded during mineral resorption from the same tergite. An assumption confirmed directly by SC $\mu$-RSI, which show no indication of ACC crystallization within the cuticle during mineral resorption. The spatial location at the proximal side of the cuticle facilitates the resorption of ACC occurring by active processes of the underlining epithelial cells. This involves lowering of the mean $\mathrm{pH}$ and an increase in the expression of calcium transport mechanisms (Ziegler, 2008, 2002; Ziegler et al., 2004; Hagedorn and Ziegler, 2002). It appears that ACC within the cuticle has at least two functions: (1) spatial modulation of the mechanical properties within the cuticle from distal towards the proximal layers (Neues et al., 2007; Hild et al., 2008) and (2) facilitation of mineral resorption from the posterior and anterior cuticle during the biphasic moult cycle of isopods (present study). The adaptive advantages of the latter are probably the shorter intervals for mineral resorption in pre and intramoult in which the cuticle is not fully mineralized and cannot provide its full support and protective functions. In particular this aspect is important in isopods that rely on a thick cuticle in avoiding predation by rolling into a sphere (Schmalfuss, 1984). These animals have a higher ACC/calcite ratio 
and larger calcium stores than those with thinner cuticles, in order to accelerate cuticle mineralization after ecdysis (Becker et al., 2005; Neues et al., 2007; Hild et al., 2008). Resorption of ACC from the cuticle during premoult was also reported for the cuticle of the crayfish Cherax quadricarinatus (Shechter et al., 2008). Crayfish resorb calcium carbonate from the cuticle to weaken the cuticle before ecdysis (Wheatly and Gannon, 1995). Most of this calcium is excreted, but a part of it is stored in gastroliths that also consist of ACC (Shechter et al., 2008).

The location below the membranous layer suggests that the transient layer inside of the anterior tergite was secreted by the hypodermal epithelium of the tergites. Disappearance of this layer just after posterior ecdysis indicates that it serves as a transitory reservoir for the mineralization of the new posterior cuticle. Its composition of ACC-microspherules and a proteinaceous organic matrix reminds to the sternal ACC deposits, although in the latter the diameters of the spherules are considerably larger.

The decrease in the anterior ACC/calcite ratio and the thickness of the anterior ACC layer concomitant to the mineralization of the posterior cuticle suggest that ACC of the anterior cuticle is used for the mineralization of the new posterior cuticle. The source for the mineralization of the anterior half of the cuticle is still not fully understood. A study on the hemolymph calcium concentration of $P$. scaber revealed that calcium remains elevated after the anterior moult, suggesting another source for calcium ions (Ziegler and Scholz, 1997). P. scaber ingests the exuviae after each half moult, suggesting that the intestinal epithelium resorbs mineral from the exuviae that still contains considerable amounts of calcium carbonate (Steel, 1993). It is of interest that in the mineralizing cuticle many pore canals can be seen that are devoid of mineral. Pore canals are formed by cellular extension of the underlining hypodermis. These are thought to play an important role during cuticle mineralization (Giraud-Guille, 1984; Roer and Dillaman, 1984; Roer, 1980). The pore canals are not visible in the fully mineralized cuticle of $P$. scaber and A. vulgare (Hild et al., 2008) and during resorption of mineral (this study). This suggests that the lumen of the pore canals will eventually become filled with mineral. Differential stability of ACC could lead to the porous appearance of the endocuticle during resorption of the mineral resulting in a higher internal surface area to speed up resorption of the mineral. Such a differential stability, brought about by components of the organic matrix, was observed in individual microspherules in the sternal deposits of P. scaber (Fabritius and Ziegler, 2003).

Combined QRA and AAS of the present study revealed a decrease of the $A C C /$ calcite ratio in the posterior cuticle between the first and second day after the anterior moult accompanied by an increase of the ratio in the anterior tergites. The changes are small, however, evaluation the ACC/calcite ratio from the SC $\mu$-RSI data qualitatively confirmed this outcome, raising the possibility that a fraction of the mineral from the new posterior cuticle is used to mineralize the new anterior tergites. A storage site within the posterior cuticle for mineralization of the anterior would be in accord with the results on other isopods. Changes in the calcium content in the anterior and posterior cuticle of the terrestrial isopod Ligia hawaiiensis suggest that the mineralized posterior part of the cuticle and possibly unknown internal calcium stores contribute to the mineralization of the anterior cuticle (Ziegler et al., 2007). Furthermore, the marine isopod Limnoria lignorum shifts $42 \%$ of the calcium retained during the posterior moult from the posterior to the anterior half of the body (Harrison and Martin, 1954).

Besides of its role as a transient reservoir for calcium carbonate (Becker et al., 2003; Levi-Kalisman et al., 2002; Raz et al., 2002; Ziegler, 1994) an important function of ACC in invertebrate biocomposites is its role as a precursor of crystalline calcium carbon- ate (Addadi et al., 2003; Beniash et al., 1997; Hasse et al., 2000; Marxen et al., 2008; Politi et al., 2004; Raz et al., 2000; Weiss et al., 2002; Weiner et al., 2005). It is of particular interest that during the mineralization of the new posterior tergites the ACC/calcite ratio decreases after an intense initial increase. This transient increase suggests that the distal region of the exocuticle is first mineralized by ACC that is then converted over time into the more stable calcite phase. Thus, at least for part of the distal calcite layer, ACC functions as a precursor phase for calcite. Failure to observe a similar transient increase of the ACC/calcite ratio during mineralization of the anterior tergites is most likely due to the longer time intervals between observation steps during mineralization of the anterior cuticle. The spatial localization by SC $\mu$ RSI of a layer of ACC that is devoid of calcite within the soft new posterior exocuticle just $1 \mathrm{~h}$ after the posterior moult supports our finding that ACC precedes calcite within the exocuticle. However, because of a thin layer of calcite in the most distal region of the cuticle we cannot exclude a direct precipitation of calcite without a preceding amorphous phase in that very distal region. A precursor function of ACC for calcite formation in the crustacean cuticle was previously suggested by Dillaman et al. (2005) based on the solubility of cuticular calcium carbonate just after its deposition in the cuticle of the dorsal carapace of Callinectus sapidus.

\subsection{Methodical aspects}

As already mentioned in the Section 3, differences in the ACC/ calcite ratio obtained when using the combination of QRA and AAS at one hand and $S C \mu$-RSI on the other may be due to variations between individuals. Intraspecific variations can be high and only a small number of tergites were analyzed by SC $\mu$-RSI, whereas for the combined QRA/AAS study the pooled tergites of 6-15 animals were analyzed for each moulting stage. In addition, since the $\mathrm{ACC} /$ calcite ratio is changing quickly during mineral resorption and deposition, differences between individuals also reflect variations in the time of animal preparation within a specific moulting stage. However, when the mineralization is almost complete, differences due to intraspecific variations or time of sampling should be rather low. Furthermore, the significant difference obtained when the two methods are compared, using data from tergites sampled 1 or 2 days after the anterior moult, argues against variations between the specimens as the reason for the difference. An overestimation of the ACC/calcite value using QRA and AAS because of the ACP content of $12 \%$ within the cuticle that was neglected in this study can by no means explain the differences between the methods. This suggests that QRA/AAS and SC $\mu$-RSI differ in the sensitivity to specific properties of the calcium carbonate phases in the tergites of these moulting stages. The decrease of the $\mathrm{ACC} /$ calcite ratio from the second day of the postmoult to the early premoult stage in both the anterior and posterior tergites as measured by QRA/AAS can be explained best by conversion of a part of the X-ray amorphous $\mathrm{CaCO}_{3}$ into calcite. It appears likely that $\mathrm{SC} \mu$ RSI does not confirm this result because the sensitivity of Raman spectroscopy to detect calcite-like lattice vibrations is higher than the sensitivity of XRD to detect calcite-like short-range order in crystallising nanoparticles converting from ACC precursors. This interpretation, however, is speculative and requires further experimental support.

\section{Acknowledgments}

We thank the Deutsche Forschungsgemeinschaft (DFG) for financial support within the Priority Program "Principles of Biomineralization" SPP 1117 (Zi 368/4-3 and Ep 22/16-3) and HASYLAB at DESY for generous allocation of beamtime. 


\section{References}

Addadi, L., Raz, S., Weiner, S., 2003. Taking advantage of disorder: amorphous calcium carbonate and its roles in biomineralization. Adv. Mater. 15, 959-970.

Al-Sawalmih, A., Li, C., Siegel, S., Fratzl, P., Paris, O., 2009. On the stability of amorphous minerals in lobster cuticle. Adv. Mater. 21, 1-5.

Becker, A., Bismayer, U., Epple, M., Fabritius, H., Hasse, B., Shi, J., Ziegler, A., 2003. Structural characterisation of amorphous calcium carbonate (ACC) in sternal deposits of the Crustacea Porcellio scaber. J. Chem. Soc. Dalton Trans. 2003, 551555.

Becker, A., Ziegler, A., Epple, M., 2005. The mineral phase in the cuticles of two species of Crustacea consists of magnesian calcite, amorphous calcium carbonate, and amorphous calcium phosphate. J. Chem. Soc., Dalton Trans. 2005, 1814-1820.

Beniash, E., Aizenberg, J., Addadi, L., Weiner, S., 1997. Amorhous calcium carbonate transforms into calcite during sea urchin larval spicule growth. Proc. Roy. Soc. London B 264, 461-465.

Boßelmann, F., Romano, P., Fabritius, H., Raabe, D., Epple, M., 2007. The composition of the exoskeleton of two crustacea: The American lobster Homarus americanus and the edible crab Cancer pagurus. Thermochim. Acta 463, 65-68.

Brecevic, L., Nielson, A.E., 1989. Solubility of amorphous calcium carbonate. J. Cryst. Growth 98, 504-510.

Dillaman, R., Hequembourg, S., Gay, M., 2005. Early pattern of calcification in the dorsal carapace of the blue crab, Callinectes sapidus. J. Morphol. 263, 356-374.

Faatz, M., Gröhn, F., Wegner, G., 2004. Amorphous calcium carbonate: synthesis and potential intermediate in biomineralization. Adv. Mater. 16, 996-1000.

Fabritius, H., Ziegler, A., 2003. Analysis of $\mathrm{CaCO}_{3}$ deposit formation and degradation during the molt cycle of the terrestrial isopod Porcellio scaber (Crustacea, Isopoda). J. Struct. Biol. 142, 281-291.

Giraud-Guille, M.-M., 1984. Fine structure of the chitin-protein system in the crab cuticle. Tissue Cell 16, 75-92.

Goldsmith, J.R., Graf, D.L., 1958. Relation between lattice constants and composition of the Ca-Mg carbonates. Am. Mineral. 43, 84-101.

Greenaway, P., 1985. Calcium balance and moulting in the crustacea. Biol. Rev. 60, $425-454$.

Gualtieri, A., 2000. Accuracy of XRPD QPA using the combined Rietveld-RIR method. J. Appl. Crystallogr. 33, 267-278.

Hagedorn, M., Ziegler, A., 2002. Analysis of $\mathrm{Ca}^{2+}$ uptake into the smooth endoplasmic reticulum of permeabilised sternal epithelial cells during the moulting cycle of the terrestrial isopod Porcellio scaber. J. Exp. Biol. 205, 1935-1942.

Hasse, B., Ehrenberg, H., Marxen, J.C., Becker, W., Epple, M., 2000. Calcium carbonate modifications of the mineralized shell of the freshwater snail Biomphalaria glabrata. Chem. Eur. J. 6, 3679-3685.

Harrison, F.M., Martin, A.W., 1954. Calcium distribution and conservation during the molting period in Limnoria lignorum (Rathke). J. Cell Comp. Physiol. 43, 247256.

Hild, S., Marti, O., Ziegler, A., 2008. Spatial distribution of calcite and amorphous calcium carbonate in the cuticle of the terrestrial crustaceans Porcellio scaber and Armadillidium vulgare. J. Struct. Biol. 163, 100-108.

Hild, S., Neues, F., Znidaršič, N., Štrus, J., Epple, M., Marti, O., Ziegler, A., 2009. Ultrastructure and mineral distribution in the tergal cuticle of the terrestrial isopod Titanethes albus. Adaptations to a karst cave biotope. J. Struct. Biol. 168, 426-436.

Knapp, M., Baehtz, C., Ehrenberg, H., Fuess, H., 2004a. The synchrotron powder diffractometer at beamline B2 at HASYLAB/DESY: status and capabilities. J. Synchr. Rad. 11, 328-334.

Knapp, M., Joco, V., Baehtz, C., Brecht, H.H., Berghaeuser, A., Ehrenberg, H., Von Seggern, H., Fuess, H., 2004b. Position-sensitive detector system OBI for high resolution X-ray powder diffraction using on-site readable image plates. Nucl. Instr. Meth. Phys. Res. A521, 565-570.

Levi-Kalisman, Y., Raz, S., Weiner, S., Addadi, L., Sagi, I., 2002. Structural differences between biogenic amorphous calcium carbonate phases using X-ray absorption spectroscopy. Adv. Funct. Mat. 12, 43-48.

Marxen, J.C., Prymak, O., Beckmann, F., Neues, F., Epple, M., 2008. Embryonic shell formation in the snail Biomphalaria glabrata: a comparison between scanning electron microscopy (SEM) and synchrotron radiation micro computer tomography (SR $\mu \mathrm{CT})$. J. Molluscan Studies 74, 19-25.

Messner, B., 1965. Ein morphologisch- histologischer Beitrag zur Häutung von Porcellio scaber latr. und Oniscus asellus 1. (Isopoda terrestria). Crustaceana 9, 285-301.

Neues, F., Ziegler, A., Epple, M., 2007. The composition of the mineralized cuticle in marine and terrestrial isopods: a comparative study. Cryst. Eng. Comm. 9, 1245-1251.

Neufeld, D.S., Cameron, J.N., 1993. Transepithelial movement of calcium in crustaceans. J. Exp. Biol. 184, 1-16.
Passano, L.M., 1960. Molting and its control. In: Waterman, T.H. (Ed.), The Physiology of Crustacea I. Academic Press, New York, pp. 473-536.

Politi, Y., Arad, T., Klein, E., Weiner, S., Addadi, L., 2004. Sea urchin spine calcite forms via a transient amorphous calcium carbonate phase. Science 306,1161 1164.

Raz, S., Weiner, S., Addadi, L., 2000. Formation of high-magnesian calcites via an amorphous precursor phase: possible biological implications. Adv. Mater. 12, 38-42.

Raz, S., Testeniere, O., Hecker, A., Weiner, S., Luquet, G., 2002. Stable amorphous calcium carbonate is the main component of the calcium storage structures of the crustacean Orchestia cavimana. Biol. Bull. 203, 269-274.

Rodriguez-Carvajal, J., 1990. Abstracts of the satellite meeting on powder diffraction of the XV Congress of the IUCr. Toulouse, France, 127.

Roer, R., Dillaman, R., 1984. The structure and calcification of the crustacean cuticle. Am. Zoo. 24, 893-909.

Roer, R.D., 1980. Mechanisms of resorption and deposition of calcium in the carapace of the crab Carcinus maenas. J. Exp Biol. 88, 205-218.

Schmalfuss, H., 1984. Eco-morphological strategies in terrestrial isopods. Symp. Zool. Soc. London 53, 49-63.

Schmidt, U., Hild, S., Ibach, W., Hollricher, O., 2005. Characterization of thin polymer films on the nanometer scale with confocal Raman AFM. Macromol. Symp. 230 133-143.

Shechter, A., Berman, A., Singer, A., Freiman, A., Grinstein, M., Erez, J., Aflalo, E.D. Sagi, A., 2008. Reciprocal changes in calcification of gastrolith and cuticle during the molt cycle of the red claw crayfish Cherax quadricarcinus. Biol. Bull. 214 $122-134$.

Steel, C.G.H., 1993. Storage and translocation of integumentary calcium during the moult cycle of the terrestrial isopod Oniscus asellus (L.). Can. J. Zool. 71, 4-10.

Strus, J., Blejec, A., 2001. Microscopic anatomy of the integument and digestive system during the molt cycle in Ligia italica (Oniscidea). In: Kensley, B., Brusca, R.C. (Eds.), Isopod systematics and evolution, vol. 13. Balkema, Rotterdam, pp. 343-352.

Strus, J., Compere, P., 1996. Ultrastructural analysis of the integument during the moult cycle in Ligia italica (Crustacea, Isopoda). Eur. J. Physiol. 431 (Suppl.), R251-R252.

Weiner, S., Sagi, I., Addadi, L., 2005. Choosing the crystallization path less traveled. Science 309, 1027-1028.

Weiss, I.M., Tuross, N., Addadi, L., Weiner, S., 2002. Mollusc larval shell formation: amorphous calcium carbonate is a precursor phase for aragonite. J. Exp. Zool. 293, 478-491.

Wheatly, M.G., Gannon, A.T., 1995. Ion regulation in crayfish: freshwater adaptations and the problem of molting. Am. Zool. 35, 49-59.

Ziegler, A., 1994. Ultrastructure and electron spectroscopic diffraction analysis of the sternal calcium deposits of Porcellio scaber Latr. (Isopoda, Crustacea). J. Struct. Biol. 112, 110-116.

Ziegler, A., 1996. Ultrastructural evidence for transepithelial calcium transport in the anterior sternal epithelium of the terrestrial isopod Porcellio scaber (Crustacea) during the formation and resorption of $\mathrm{CaCO}_{3}$ deposits. Cell Tissue Res. 284, 459-466.

Ziegler, A., 1997. Ultrastructural changes of the anterior and posterior sternal integument of the terrestrial isopod Porcellio scaber Latr. (Crustacea) during the moult cycle. Tissue Cell 29, 63-76.

Ziegler, A., 2002. X-ray microprobe analysis of epithelial calcium transport. Cell Calcium 31, 307-321.

Ziegler, A., 2003. Variations of calcium deposition in terrestrial isopods. In: Sfenthourakis, S., De Araujo, P.B., Hornung, E., Schmalfuss, H., Taiti, S. Szlavecz, K. (Eds.), Crustaceana Monographs. Koninklijke Brill NV, Leiden, pp. 299-309.

Ziegler, A., 2008. The cationic composition and $\mathrm{pH}$ in the moulting fluid of Porcellio scaber (Crustacea, Isopoda) during calcium carbonate deposit formation and resorption. J. Comp. Physiol. B 178, 67-78.

Ziegler, A., Miller, B., 1997. Ultrastructure of $\mathrm{CaCO}_{3}$ deposits of terrestrial isopods (Crustacea, Oniscidea). Zoomorphology 117, 181-187.

Ziegler, A., Scholz, F.H.E., 1997. The ionic hemolymph composition of the terrestrial isopod Porcellio scaber Latr. during molt. J. Comp. Physiol. B 167, 536-542.

Ziegler, A., Weihrauch, D., Towle, D.W., Hagedorn, M., 2002. Expression of $\mathrm{Ca}^{2+}$ ATPase and $\mathrm{Na}^{+} / \mathrm{Ca}^{2+}$-exchanger is upregulated during epithelial $\mathrm{Ca}^{2+}$ transport in hypodermal cells of the isopod Porcellio scaber. Cell Calcium 32, 131-141.

Ziegler, A., Weihrauch, D., Hagedorn, M., Towle, D.W., Bleher, R., 2004. Expression and polarity reversal of $\mathrm{V}$-type $\mathrm{H}^{+}$-ATPase during the mineralizationdemineralization cycle in Porcellio scaber sternal epithelial cells. J. Exp. Biol. 207, 1749-1756.

Ziegler, A., Hagedorn, M., Ahearn, G.A., Carefood, T.H., 2007. Calcium translocations during the moulting cycle of the semiterrestrial isopod Ligia hawaiiensis (Oniscidea, Crustacea). J. Comp. Physiol. 177, 99-108. 